\title{
Infrared Absorption Spectra of Some Experimental Glasses Containing Rare Earth and Other Oxides
}

\author{
By Ralph Stair and Conrad A. Faick
}

\begin{abstract}
This paper gives spectral transmission data on soda lime glass containing rare earth (Y, Pr, Nd, Sm, Gd, Er) or other coloring oxides (V, Cr, Mn, Co, Ni, U) in the spectral region of 0.7 to 4.5 microns.
\end{abstract}

\section{Introduction}

In connection with experiments upon glass spectral filters and upon the physical properties of certain other glasses as a function of their composition, infrared transmissions were méasured upon a number of soda-lime-silica glasses containing some rare earth and other coloring oxides. All glasses were made with the same basic composition, namely: $\mathrm{SiO}_{2}, 71.4$ percent; $\mathrm{Na}_{2} \mathrm{O}, 18.4$ percent; and $\mathrm{CaO}, 10.2$ percent, as computed from the batch materials. Calcium and anhydrous sodium carbonate of reagent quality and powdered crystalline quartz were employed for the base glass. The other materials were added in the form of oxides.

These glasses were melted in a 25 -ml platinum crucible, in a platinum-resistance furnace. The melting procedure followed very closely that used in previous experimental work [1]* and all glasses received the same treatment. Data on the specific refraction and dispersion of some of these glasses have been published elsewhere [12].

The samples obtained often contained a few seeds and a small amount of striation which may have caused small errors in absorption measurements. However, as the complete infrared absorption curve was obtained through the same

\footnotetext{
*Figures in brackets indicate the literature references at the end of this paper.
}

area of the sample, relative values between the different wavelengths should be adequate.

The rare-earth oxides used in the production of these glasses were from the James collection that had been acquired by the Bureau. ${ }^{1}$ According to tests made by the Spectroscopy Section of this Bureau, these rare-earth oxides contained varying amounts of impurities, especially other rare-earth materials, but their purity was judged to be adequate for the purposes of this report.

The praseodymium oxide contained small amounts of lanthanium and yttrium in addition to traces of calcium, copper, iron, magnesium, and silicon. The neodymium oxide was of high purity, containing only traces of calcium, copper, iron, magnesium, and silicon. The samarium oxide was especially good, containing, in addition to small amounts of calcium and silicon, only traces of magnesium and lead, with praseodymium doubtful. The gadolinium oxide contained about 10 percent of europium, about 1 percent each of bismuth and magnesium, in addition to a small amount of calcium, traces of erbium, silicon, and samarium, and possibly traces of potassium and lead. The erbium oxide was not subjected to as thorough spectrochemical study, but it contained

\footnotetext{
1 Collection of rare-earth materials prepared by the late Professor James of the University of New Hampshire and subsequently purchased from the University by the National Bureau of Standards.
} 
about 1 percent of yttrium, smaller amounts of holmium and thulium, and traces of scandium and ytterbium. The purity of the yttrium oxide is not known.

An examination of the different absorption curves shows no significant bands for yttrium (see fig. 2) or for europium (see curve 6 for gadolinium, which contains Eu as an impurity) nor the presence of overlapping of absorption bands that might be expected in mixed materials, where the same impurities are present for a number of the glasses. Hence, in most cases, at least, these impurities were in very small amount or else of a type that is known to produce relatively weak absorption within the region of 0.7 to $4.5 \mu$. Reagent quality oxides were used for the other coloring materials.

All glasses having a silica base show a high absorption in the region of 2.8 to $4.5 \mu$, which is caused by some combination of silica with water and other base materials of which the glass is composed. Because this silica absorption may be made to vary between wide limits [9] in the region of $2.9 \mu$ simply by controlling the amount of water within the glass, it is impossible to attempt to make accurate calculations on comparative transmissions within this silica absorption region. Furthermore, analysis of the oxide absorption in the region of 2.8 to $4.5 \mu$ is greatly

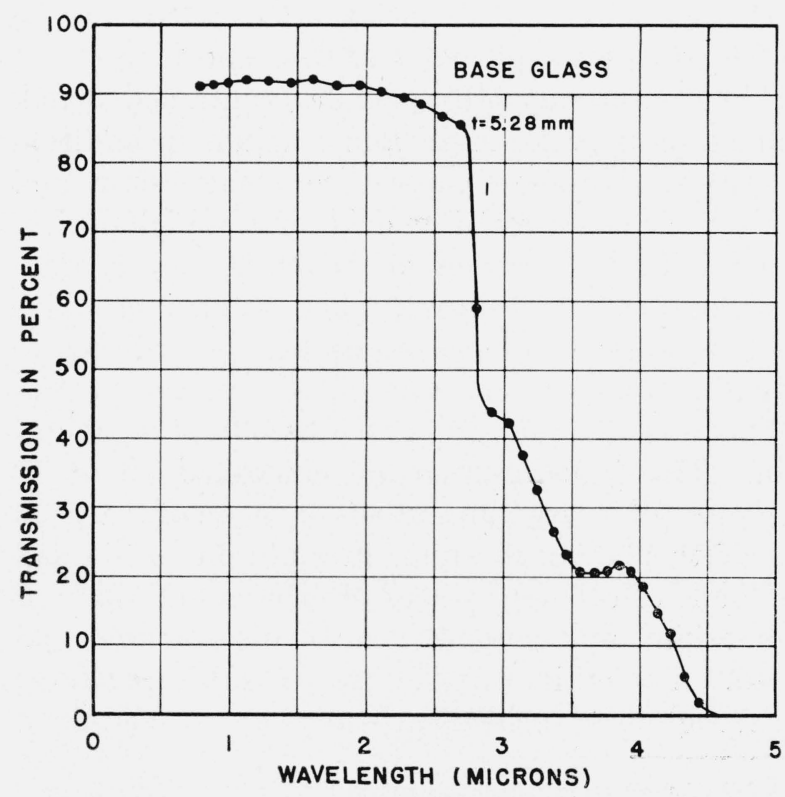

Figure 1. complicated as the result of the high absorption in the base glass. Either because of this high and variable absorption in the base glass or because the oxides studied have no characteristic bands in this region, no absorption bands between 2.8 and $4.5 \mu$ were discovered that could positively be attributed to the oxides added.

The transmission of the base glass is given in figure 1. This glass shows no absorption bands at wavelengths shorter than about $2.8 \mu$. Beyond this wavelength the silica absorption increases rapidly with increase in wavelength.

The glasses vary somewhat in thickness. For several of them two thicknesses were available. This is often useful in infrared studies, because a proper selection of thickness of the specimen permits the structure of the absorption spectrum to be exhibited to best advantage. In this work the more suitable sample was chosen.

\section{Instruments and Methods}

For a detailed discussion of the experimental procedure, reference is made to previous publications $[3,4,5,6,7,8]$. The spectroradiometer consisted of a mirror spectrometer, with mirrors $50 \mathrm{~cm}$ in focal length. A small fluorite prism on a Wadsworth mounting was employed.

The observations were made by the "point by point" method. A portable vacuum thermopile of bismuth-silver, connected with an iron-clad Thomson galvanometer, was used for measuring the radiation. The source of radiation was a Nernst glower, focused upon the entrance slit of the spectrometer by means of a large concave mirror of 1-m focal length. The galvanometer readings were read visually and recorded. The sample was placed in front of the entrance slit of the spectrometer by means of a mechanical carriage which placed it in the same position for each wavelength. The effective spectral slit width varied from about 0.17 at 2 to 0.07 at $4.5 \mu$.

\section{Spectral-Transmission Data}

A brief description is given of the glass and its special transmission characteristics. A general summary covering the kinds and amounts of oxides added is given in table 1 . The glass numbers correspond to the same samples examined in the visible spectrum and reported on elsewhere [2]. 
TABLE 1.-Amount of oxide added to the base glass

\begin{tabular}{|c|c|c|c|}
\hline $\begin{array}{l}\text { Glass } \\
\text { No. }\end{array}$ & Weight of oxide added & $\begin{array}{l}\text { Thick- } \\
\text { ness }\end{array}$ & $\begin{array}{l}\text { Index of re- } \\
\text { fraction } \\
\text { wavelength, }\end{array}$ \\
\hline & Percent & $m m$ & \\
\hline 1 & Base glass .......... & 5. 28 & 1. 5224 \\
\hline 2 & $3.0 \quad \mathrm{~V}_{2} \mathrm{O}_{5} \ldots \ldots$ & 4. 73 & 1.5285 \\
\hline 3 & $1.0 \mathrm{Cr}_{2} \mathrm{O}_{3} \ldots$ & 4. 21 & 1. 5255 \\
\hline 4 & $1.0 \mathrm{Mn} \mathrm{O}_{2} \ldots$ & 4. 40 & 1. 5237 \\
\hline 5 & $0.04 \mathrm{Co} \mathrm{O}_{\ldots}$ & 4. 22 & 1.5216 \\
\hline $6 \mathrm{a}$ & $.05 \mathrm{Ni} \mathrm{O} \ldots$ & 4. 22 & -..........- \\
\hline 6 & $.50 \mathrm{Ni} \mathrm{O}$ & 4.47 & \\
\hline 9 & $10.0 \quad \mathrm{Y}_{2} \mathrm{O}_{3} \ldots$ & 6. 81 & 1. 5439 \\
\hline 13 & 10.0 $\mathrm{Pr}_{6} \mathrm{O}_{11 \ldots \ldots}$ & 7.13 & - \\
\hline 15 & 10. $0 \quad \mathrm{Nd}_{2} \mathrm{O}_{3} \ldots$ & 7. 27 & -..... \\
\hline 18 & $10.0 \mathrm{Sm}_{2} \mathrm{O}_{3 \ldots} \ldots$ & 6.80 & $\ldots$ \\
\hline 19 & $10.0 \mathrm{Gd}_{2} \mathrm{O}_{3} \ldots$ & 6. 28 & 1. 5343 \\
\hline 20 & $10.0 \quad \mathrm{Er}_{2} \mathrm{O}_{3} \ldots \ldots$ & 6. 52 & -........... \\
\hline 23 & $3.0 \quad \mathrm{U}_{3} \mathrm{O}_{8} \ldots$ & 2. 52 & -........... \\
\hline
\end{tabular}

\section{Yttrium Oxide Glass}

No appreciable absorption in the near infrared is caused by yttrium oxide $\left(\mathrm{Y}_{2} \mathrm{O}_{3}\right)$ when added in an amount of 10 percent (see fig. 2). Neither was

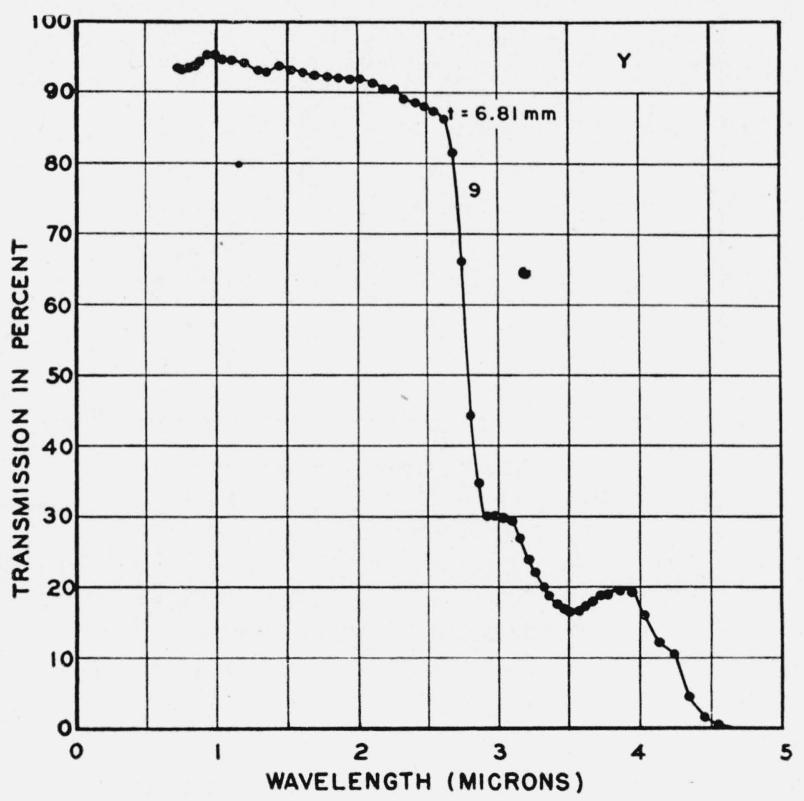

Figure 2.

any absorption observed within the visible spectrum (see reference [2]).

A comparison of the absorption curve for yttrium oxide glass with those for the base glass and the erbium and gadolinium oxide glasses (see figs. 1, 6, and 7) indicates the possibility of some general absorption in the region of 2.7 to $4.2 \mu$. However, differences in thickness and amounts of water within the glass may account for the greater absorption in this region.

\section{Praseodymium Oxide Glass}

Two strong absorption maxima occur at about 1.45 and $1.90 \mu$ as the result of the addition of praseodymium $\left(\mathrm{Pr}_{6} \mathrm{O}_{11}\right)$ in the amount of 10 percent. Weak bands occur at about 0.76 and $1.0 \mu$ (see fig. 3). The general shape of the transmission

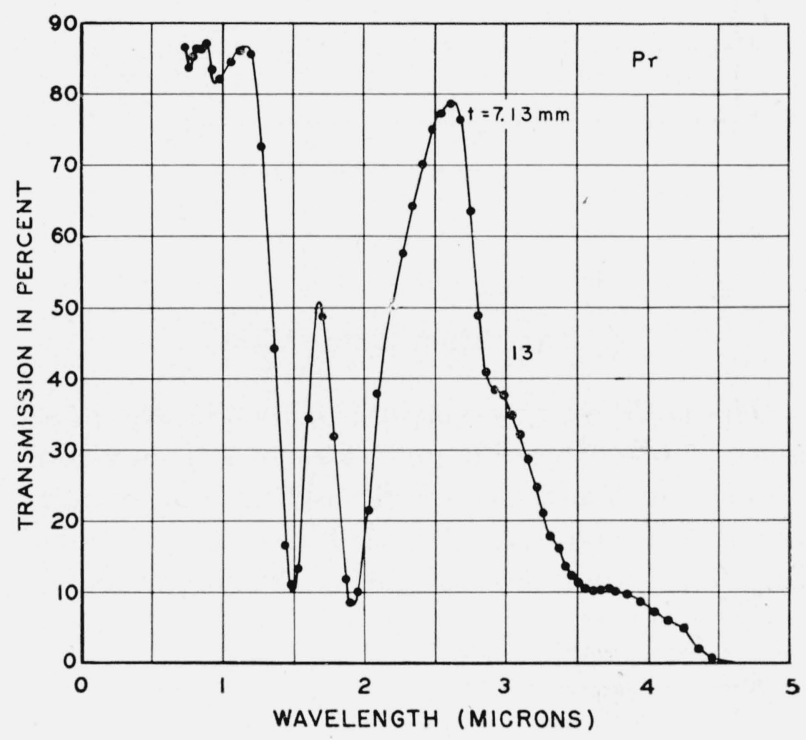

Figure 3.

curve indicates the possibility of additional bands in the region of 2.4 and $4.0 \mu$. Absorption in the visible spectrum gives this glass a light yellowish green color.

\section{Neodymium Oxide Glass}

The addition of neodymium $\left(\mathrm{Nd}_{2} \mathrm{O}_{3}\right)$ in the amount of 10 percent results in three strong absorption bands at about $0.77,1.63$, and $2.43 \mu$ (see fig. 4). It is to be expected that this material would produce a number of absorption bands in the near infrared judging from the number and intensity of the bands in the visible spectrum [2], which give this glass its bright-purple hue. 


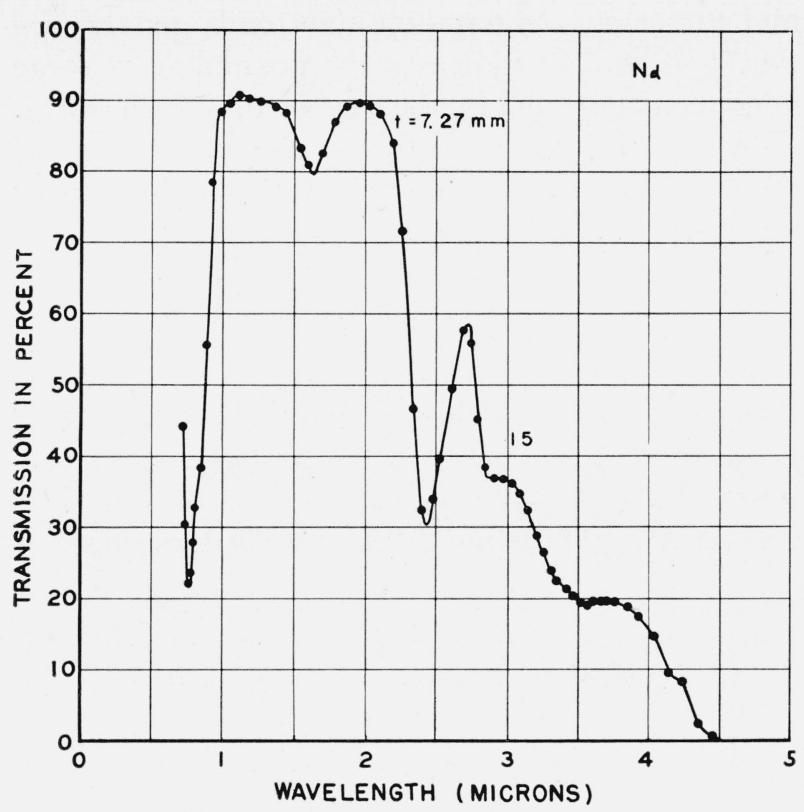

Figure 4.

\section{Samarium Oxide Glass}

The addition of samarium oxide $\left(\mathrm{Sm}_{2} \mathrm{O}_{3}\right)$ in an amount of 10 percent gives rise to a very strong absorption band at about $1.47 \mu$, and weaker bands at about $1.1,1.92,2.62$, and $4.1 \mu$ (see fig. 5). The strong band at $1.47 \mu$ almost completely

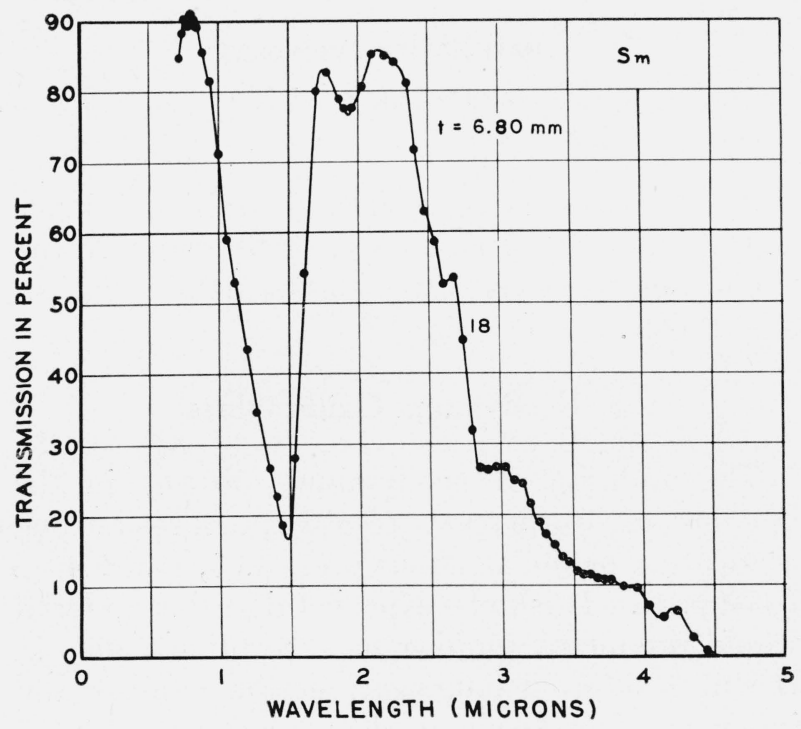

Figure 5 . masks the one in the neighborhood of $1.1 \mu$. The presence of so many bands within this part of the infrared spectrum suggests the possibility of other bands at longer wavelengths. Hence it would be interesting to study this material incorporated into a special infrared transmitting glass. Absorption in the visible spectrum gives this glass a light yellowish hue.

\section{Gadolinium Oxide Glass}

No appreciable absorption occurs in the near infrared (or in the visible spectrum) because of the addition of gadolinium oxide $\left(\mathrm{Gd}_{2} \mathrm{O}_{3}\right)$ (see fig. 6).

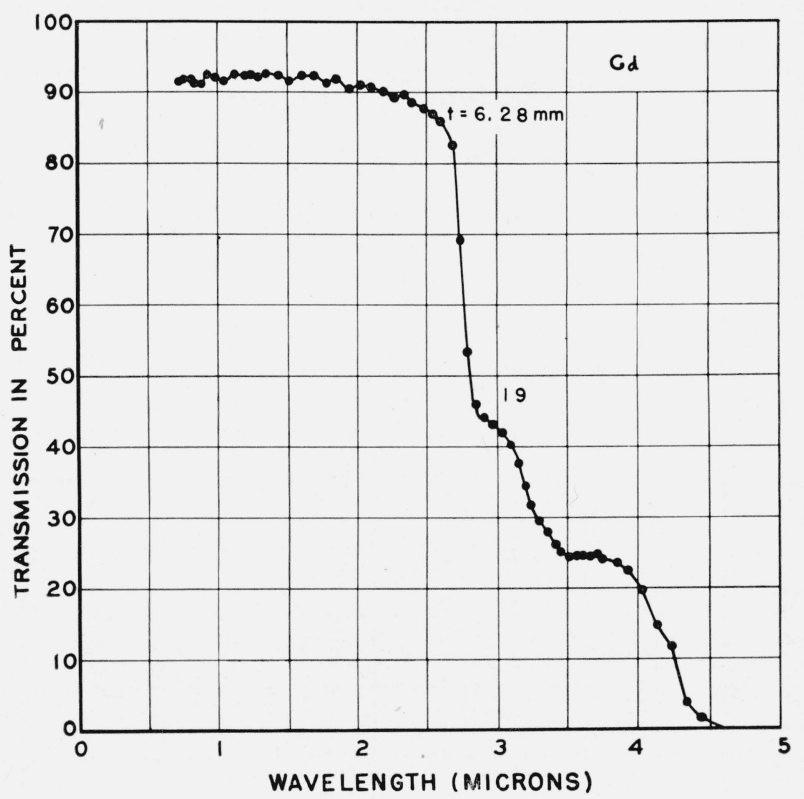

Figure 6.

\section{Erbium Oxide Glass}

The addition of erbium oxide $\left(\operatorname{Er}_{2} \mathrm{O}_{3}\right)$ in an amount of 10 percent gives rise to one strong absorption band at about $1.52 \mu$ and two weaker bands at about 0.80 and $0.95 \mu$, respectively (see fig. 7). A comparison with the transmission curve for gadolinium (fig. 6), which probably produces but little or no absorption in the infrared between 0.6 and $4.5 \mu$, indicates no other important absorption bands shorter than $4.5 \mu$. Absorption in the visible spectrum gives this glass a light-pink color. 


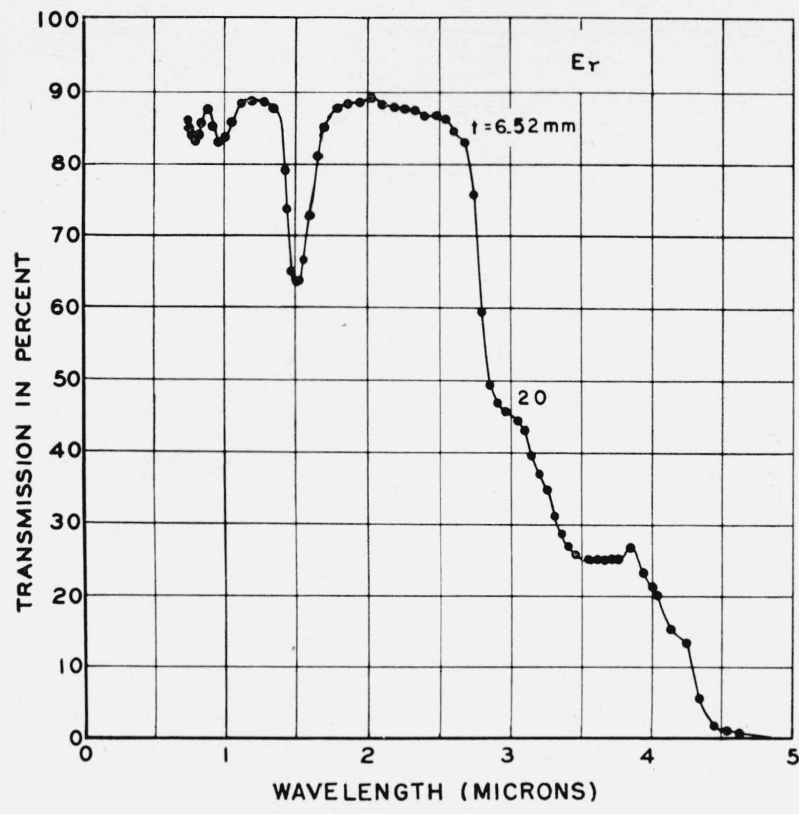

Figure 7.

\section{Other Oxide Glasses}

The addition of vanadium $\left(\mathrm{V}_{2} \mathrm{O}_{5}\right)$, cobalt $(\mathrm{CoO})$, nickel $(\mathrm{NiO})$, or uranium $\left(\mathrm{U}_{3} \mathrm{O}_{8}\right)$ oxide in small amounts (see table 1) produce strong absorption bands in the spectral region between 1 and $4 \mu$ (see figs. 8, 11,12, and 13). It is to be noted that much smaller concentrations of these metals were

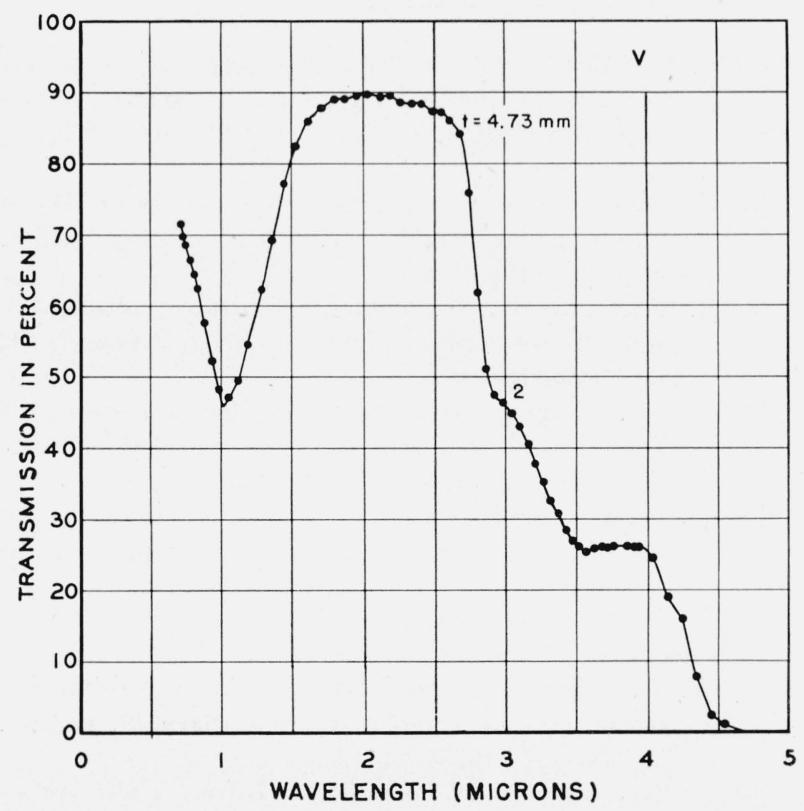

Figure 8. required to produce absorption of magnitude similar to that resulting from the addition of 10 percent of some of the rare-earth oxides. In the case of the addition of chromium $\left(\mathrm{Cr}_{2} \mathrm{O}_{3}\right)$ and manganese $\left(\mathrm{MnO}_{2}\right)$ oxides, little change in absorption occurs within the near infrared region (see figs. 9 and 10).

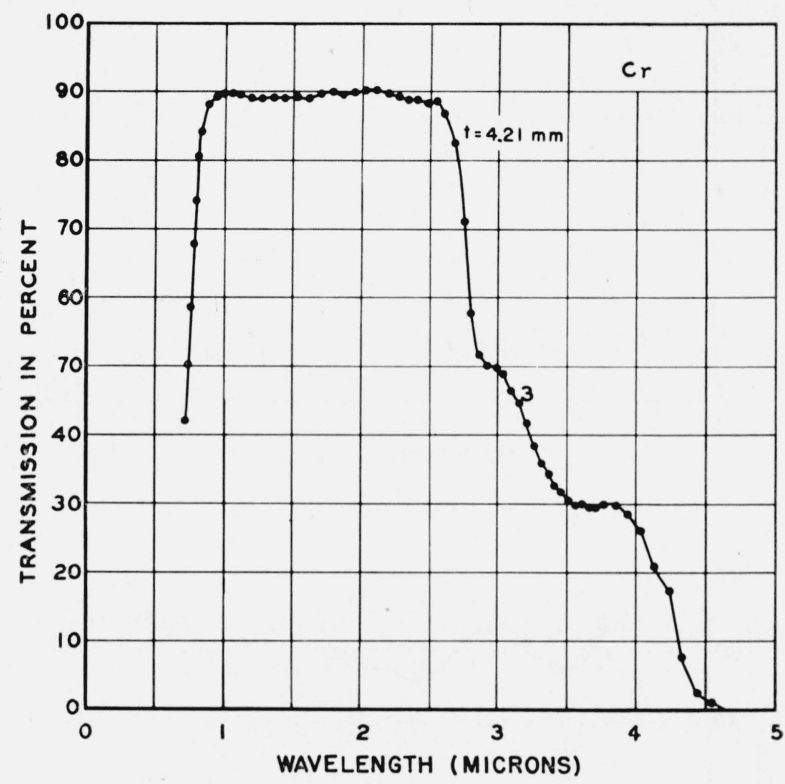

Figure 9.

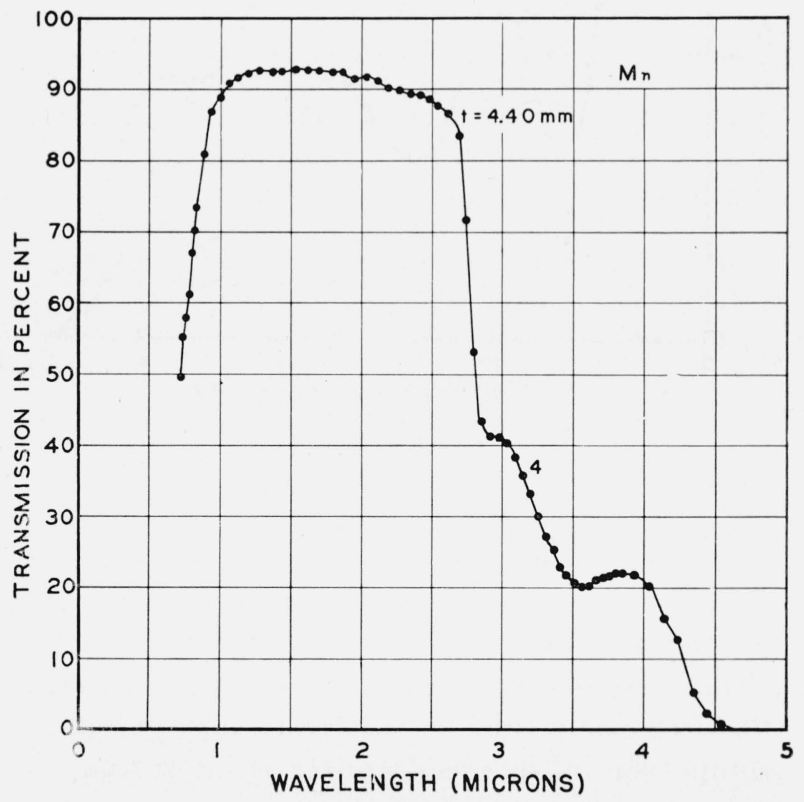

Figure 10. 


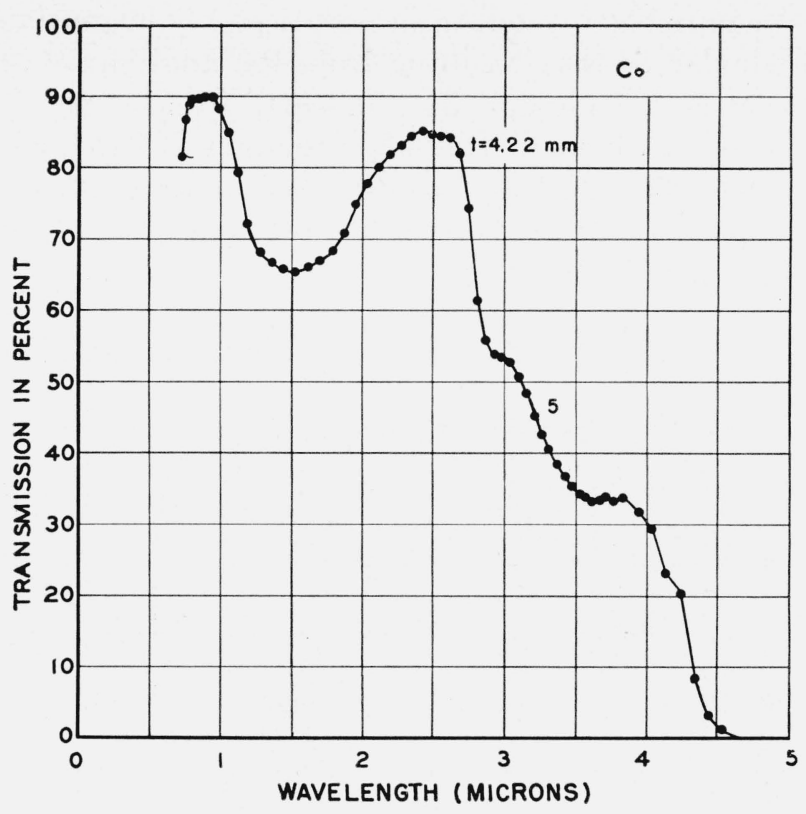

Figure 11.

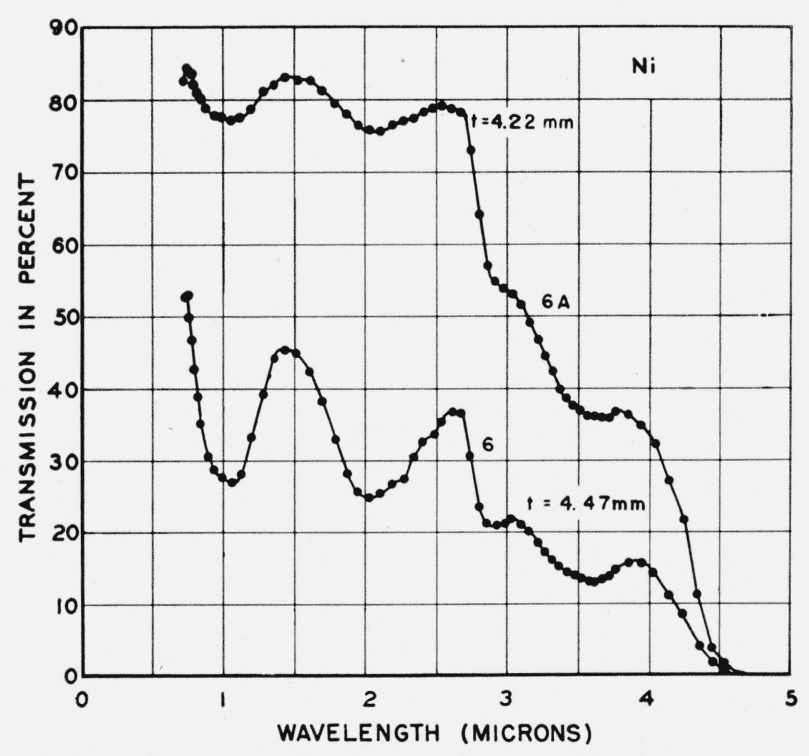

Figure 12.

According to the work of Kiess, Humphreys, and Laun upon its atomic spectrum, uranium is a rare-earth type element and is the homologue of neodymium [10]. It has the same valence electron structure and we would expect, therefore, its behavior would be similar to neodymium. A comparison of figures 4 and 13 is interesting.

Each of the metal oxides also produces a large amount of absorption in the visible spectrum resulting in a distinct color for each glass. The

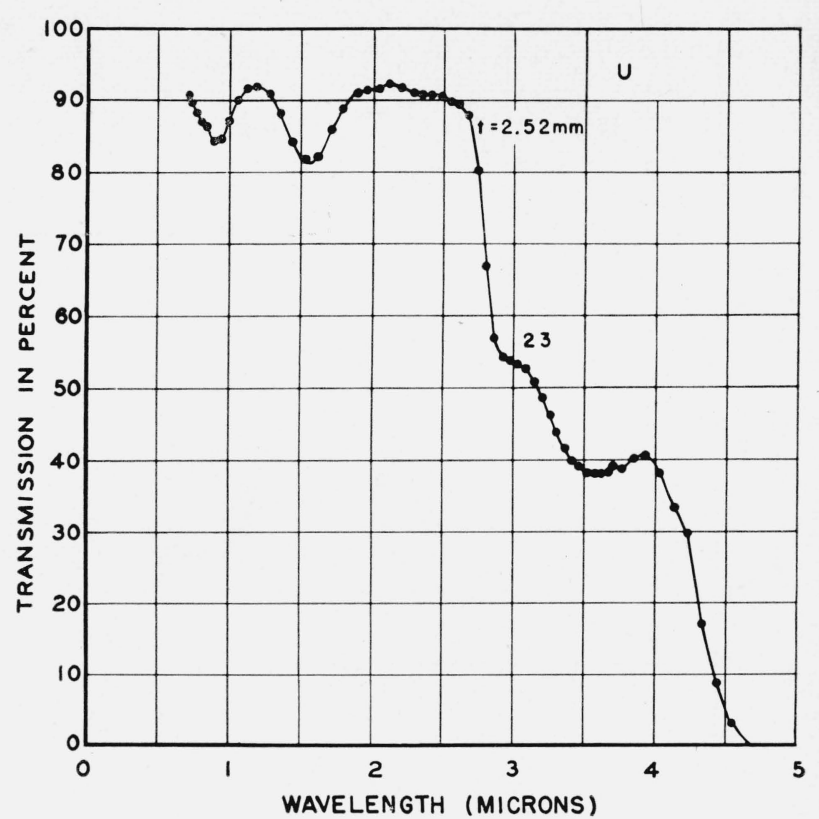

Figure 13.

colors resulting in the glasses of this group are as follows for the different oxides: Cobalt, pale blue; nickel, light to dark smoke to dark purple; vanadium, light yellow to yellow green (similar to novial $B$ ); uranium, light yellow (near novial $C$ ); chromium, green to yellowish green; and manganese, amethyst.

\section{References}

[1] C. A. Faick and A. N. Finn, The index of refraction of some soda-lime-silica glasses as a function of the composition, BS J. Research 6, 993 (1931) RP320; J. Am. Ceram. Soc. 7, 518 (1931).

[2] C. A. Faick, The visible absorption spectra of glasses containing rare earth and other coloring oxides. Publication pending.

[3] R. Stair and W. W. Coblentz, Infrared absorption spectra of some plant pigments, BS J. Research 11, 703 (1933) RP617.

[4] W. W. Coblentz, Constants of spectral radiation of a uniformly heated inclosure, or so-called black body, BS Bul. 10, 1 (1913) S204.

[5] W. W. Coblentz, Sensitivity and magnetic shielding tests of a Thomson galvanometer for use in radiometry, BS Bul. 13, 423 (1916) S282.

[6] W. W. Coblentz, A portable vacuum thermopile, BS Sci. Pap. 17, 187 (1921) S413.

[7] W. W. Coblentz, Infrared transmission and refraction data on standard lens and prism material, BS Sci. Pap. 16, 701 (1920) S401.

[8] R. Stair and W. W. Coblentz, Infrared absorption spectra of plant and animal tissue and of various other substances, J. Research NBS 15, 295 (1935) RP830. 
[9] Anna J. Harrison, Effect of water content on infrared transmission of simple glasses. Paper given before the Glass Division at the Buffalo meeting of the Amer. Ceram. Soc., May 1, 1946.

[10] C. C. Kiess, C. J. Humphreys, and D. D. Laun, Preliminary report on the description and analysis of the first spectrum of uranium, J. Research NBS 37, 57 (1946) RP1729.
[11] Woldeman A. Weyl, Colored glasses, J. Soc. Glass Tech. 28, 158 (1944).

[12] John C. Young and Alfred N. Finn, Effect of composition and other factors on the specific refraction and dispersion of glasses, J. Research NBS $\mathbf{2 5 ,} 759$ (1940) RP1352.

Washington, June 5, 1946. 